Session 2793

\title{
Improving Multiple Outcomes for Minority Engineering Students: the Math Excellence Workshop at Clemson University
}

\author{
Matthew W. Ohland, Ronald E. Chrestman, Susan J.S. Lasser \\ General Engineering / Institutional Research / Programs for Educational \\ Enrichment and Retention, Clemson University, Clemson, SC 29634
}

\begin{abstract}
A longitudinal study of Black students participating in the Math Excellence Workshop at Clemson University has found statistically significant benefit to multiple outcomes. The workshop is designed after the Treisman workshop model, which has been shown previously to be beneficial for minority student development. In addition to the value of adding to the base of evidence supporting the use of this model, the result of this study is significant because of the breadth of outcomes and the length of the period studied. The study compares the performance of program participants to a control group of minority students from the same cohorts and with a similar matriculation profile in terms of age and of a predicted grade point ratio based on SAT / ACT scores, high school rank in class, and quality of high school.
\end{abstract}

\section{Black student retention and the Treisman approach to improving it}

High failure rates in introductory college mathematics courses, notably among underrepresented students, have been of concern for many years. ${ }^{1,2}$ Table 1 shows graduation rates for Black students at Clemson University and nationwide. The six-year graduation rate for Blacks in STEM majors and in any major appear fairly stable nationwide, although these data are unavailable prior to the 1992 cohort, since this was the first longitudinal study by the Center for Institutional Data Exchange and Analysis, released in the 1999-2000 SMET Retention Report. ${ }^{3}$

Table 1. Graduation rates of earlier cohorts of Black students at Clemson and nationwide

\begin{tabular}{|l|l|}
\hline Black 6-year graduation rate in STEM majors, nationwide, 1992 cohort & $24 \%{ }^{4}$ \\
\hline Black 6-year graduation rate in any major, nationwide, 1992 cohort & $40 \%{ }^{5}$ \\
\hline & \\
\hline Black 6-year graduation rate in engineering, Clemson, 1984 cohort & $28 \%$ est. \\
\hline Black 6-year graduation rate in any major, Clemson, 1984 cohort & $52 \%{ }^{6}$ \\
\hline
\end{tabular}

The graduation rate in engineering for the Clemson 1984 cohort is estimated, as precise data could not be found. Generally, the retention rates were similar to the nationwide averages, especially in that they painted a bleak picture of Black student success.

The search for causes and solutions has led to an investigation not only of teaching methods and curricula but also of cultural issues within academia. Treisman had found that an important factor in the scholastic success of Asian American students is their comfort with the process of group

Proceedings of the 2003 American Society for Engineering Education Annual Conference \& Exposition Copyright (C) 2003, American Society for Engineering Education 
study. Group study, or collaborative learning, is an extremely effective method for understanding technical material: in the process of explaining and defending their methods of problem-solving, students arrive at a much more sophisticated understanding of the concepts than they can achieve alone. Treisman concluded that since Asian American students are already familiar with this method by the time they enter college, they can study more effectively. Further, they easily combine group study with digressions to social and college adjustment topics, a supportive process which eases their entry into a new environment. Treisman found that other groups of students, including Black students, greatly improved their calculus grades when taught these collaborative learning techniques and encouraged to use them. ${ }^{7}$

In 1978, with the help of a grant from the Department of Education's Fund for the Improvement of Postsecondary Education (FIPSE), Uri Treisman implemented a newly created calculus honors curriculum titled the Mathematics Workshop Program (MWP) at the University of California, Berkeley. The MWP was specifically designed to address the proximal causes of high attrition in mathematics-related disciplines among underrepresented student groups. The results of this initial endeavor were very impressive. "Black and Latino participants... substantially outperformed not only their minority peers, but their White and Asian classmates as well," says Treisman. ${ }^{8}$ Inspired by the impressive successes of the Mathematics Workshop Program at Berkeley, other colleges and universities have implemented Treisman's model, adapting it as necessary to meet their specific needs. The problems uncovered by Treisman in the 1970s persist. Data from the 1990s show that the achievement gaps between white and minority students are once again growing, and there is little evidence that state-sponsored systemic reform policies have had their intended effects. ${ }^{9}$ Our research indicates that systemic reform has failed to improve Black student achievement because the lessons of Treisman's research did not reach the intended audience.

Central to the Treisman model is that the workshop is not remedial. The workshop is designed as a challenging approach to the subject material, but the students are coached to cooperate in order to learn the material.

\section{The College of Engineering and Science at Clemson University}

Clemson University is a land-grant institution located in rural upstate South Carolina. Its population of approximately 14,000 undergraduates is drawn largely from in-state high schools. Originally a technical school, Clemson is still considered to be largely technically oriented, and the College of Engineering and Science is the largest college in the University. Currently, the College

of Engineering and Science has more than 3,600 undergraduates, of whom about 10.5 percent are Black.

Clemson's General Engineering program has coordinated a common first-year engineering curriculum since 1985. ${ }^{10}$ The program was known as Freshman Engineering until 1993. During the 1994-95 academic year, the University was restructured from nine Colleges into five. The newly created College of Engineering and Science included the departments of astronomy/physics, chemistry, computer science, geology, mathematics, and textiles. ${ }^{11}$ The General Engineering curriculum includes Calculus I (Clemson's MthSc 106) and Calculus II Proceedings of the 2003 American Society for Engineering Education Annual Conference \& Exposition Copyright (C) 2003, American Society for Engineering Education 
(MthSc 108); later math classes are required by the students' disciplinary majors. At the time covered by this study, students who required mathematics preparation before beginning Calculus I took Pre-Calculus (MthSc 105). It is important to this study to note that Clemson policy requires a $\mathrm{C}$ or better in all prerequisite courses, so a grade of $\mathrm{D}$ is considered unacceptable for the purposes of making progress in the mathematics sequence.

\section{The PEER office at Clemson University}

The Programs for Educational Enrichment and Retention (PEER) Office began operation in August 1987. It offered an intensive, student-to-student mentoring effort for new Black students entering Clemson University's then-College of Engineering. Although many other institutions offered mentoring at the time, the program was unique in that it was proactive. New students did not have to apply for a mentor; they were all assigned one. From the beginning PEER has been remarkable successful in retaining students from the freshman to the sophomore year in engineering and science, averaging better than 80 percent each year.

The PEER Office is directed by Susan J.S. Lasser. She and Dr. Robert Snelsire, a professor of electrical engineering, have been in charge of PEER since its inception in 1987. A counselor by training, Lasser was one of the first to earn the national Presidential Award for Excellence in Science, Mathematics, and Engineering Mentoring. Snelsire, who also founded a successful program at Clemson for academically talented minority high school students, serves as PEER's faculty advisor.

When the College of Engineering and Science was created in 1994-95, PEER expanded to include Black students from the science majors. An increase in the number of Hispanic/Latino students in the College led Snelsire and Lasser to include these students in PEER as well.

In 1989-90, incoming students' scores on the mathematics portion of the SAT II were used by the University to determine the students' placements in mathematics classes. Students scoring lower than 550 were placed in the University's five-credit pre-calculus course (MthSc 105). In the engineering curriculum, these students were considered to be at risk; historically, those who entered with math SAT scores below 550 have been much less likely to complete the engineering curriculum. More than one third of each Black engineering cohort fell in this category.

Snelsire and Lasser determined that with the mentoring program already in place, the most powerful way to affect retention would be to assist those who were statistically at highest risk to fail due to poor mathematics preparation. They had become interested in attempting to replicate the results of Treisman. In 1990 Snelsire was approached by Mr. Michael Hodges of the Savannah River Nuclear Site about using available federal funds to create a summer program for incoming college students. This would allow the opportunity both to provide intensive mathematics instruction and to teach the collaborative learning skills Treisman had identified as crucial. Snelsire accepted the funding and the two used it to create the first Math Excellence Workshop (MEW).

Proceedings of the 2003 American Society for Engineering Education Annual Conference \& Exposition Copyright $\left({ }^{\circ} 2003\right.$, American Society for Engineering Education 


\section{The history of Clemson's Math Excellence Workshop (MEW)}

Snelsire and Lasser decided that one way to indicate to participating students that they were fully capable of competing at the college level was to place them in a regular University math class as part of the Math Excellence Workshop. No special sections of the MthSc 105 Pre-Calculus course were requested. Instead Snelsire met with the math department, explained the MEW program, and asked that the students be split between as many sections of the course as were planned for the second summer session.

In addition to this course, MEW students were required to participate in a daily, two-hour collaborative seminar based on Treisman's calculus workshop. Snelsire approached Ms. Peggy Garner, a University mathematics professor with years of high school teaching experience, to design and teach this seminar. The seminar followed the topics covered in Pre-Calculus, but covered the material at a more sophisticated level, using word problems that required group work to solve. As Treisman had described, students worked in small groups, analyzing the problems presented, discussing possible solutions, and thereby learning the techniques of group study. Ms. Garner kept formal instruction to a minimum and presented herself as a resource to be called upon when needed, rather than assuming a traditional teaching role. Ms. Garner was assisted by a student tutor who was also available during seminar to move from group to group, answering questions and fostering group discussion. The tutor offered a "study hall" five nights a week in the dorm to answer questions about homework from the regular course. Attendance at study hall was voluntary. Lasser offered four lectures during seminar time on test anxiety, test taking skills, time management, and how to read a textbook efficiently.

Two more undergraduate African American students were offered room and board in exchange for serving as counselors to the MEW students. Their function was not authoritative, as Lasser and Snelsire agreed that it was counterproductive to impose any kind of curfew or other rule not normally imposed by the University on resident undergraduates. The counselors provided a friendly ear, organized one or two social events, and, on weekends, drove students who wished to get off campus to surrounding towns and to church.

Invitations to attend the first MEW were sent in April of 1990 to all accepted African American students who planned to major in engineering and whose math SAT scores (SAT II scores not being available so early) were below 550. The letters congratulated the students on admission, described MEW as an honors seminar and "an intensive introduction to college mathematics" and offered them a chance to participate. Students were accepted on a first-come, first-served basis. Twenty-seven students decided to participate.

The MEW format has remained consistent since its inception, although the numbers of student participants and of personnel have increased, and funding sources have shifted. A second tutor was added in the second year of the program; the structure of one professor and two tutors in each seminar section has remained constant since then.

Proceedings of the 2003 American Society for Engineering Education Annual Conference \& Exposition Copyright $\left({ }^{\circ} 2003\right.$, American Society for Engineering Education 
Savannah River continued to fund the program for two more years. In the fourth year (1993), funding was allocated from the College and from the South Carolina Alliance for Minority Participation, a National Science Foundation-funded coalition of state schools. Funding is still received from these two sources. Due to the requirements of the National Science Foundation, students in mathematics and the sciences were also invited to participate in MEW.

In 1995, additional funding was allocated from both sources to add a section of first-semester calculus to MEW. As with the pre-calculus class, students were assigned to the regular calculus course taught by the mathematics department, and split between two sections of the course. Snelsire chose Dr. Joel Brawley to teach the MEW calculus seminar. (A noted professor and educator, Dr. Brawley was already a University Alumni Distinguished Professor and winner of the University's Class of '39 Award for Excellence at the time. Awards Brawley has garnered since joining the MEW faculty include the Haimo Award for Distinguished College or University Teaching of Mathematics [the nation's highest mathematics teaching award] and becoming the 2001 South Carolina Governor's Professor of the Year.)

With the addition of a calculus component, all Black and Hispanic/Latino American students who were accepted into the College of Engineering and Science were invited to participate in MEW. A few of the students in this expanded pool had taken the Advanced Placement (AP) exam and might receive credit for first-semester calculus. Some others had taken calculus in high school and therefore had the option of skipping first-semester calculus and going straight to second-semester calculus at matriculation. Each of these subsets of students was told they would not earn additional class credit by participating, but would be included in MEW if they wished to attend. Students who were still waiting for AP credit scores when MEW began were told they could withdraw from the summer class if they chose after receiving their AP scores. Although a few students that semester (and every summer since) received scores that would have allowed them to place out of first-semester calculus and withdraw from MEW, none has ever done so.

In 1997, following a change in enrollment policy, Lasser offered the MEW participants the opportunity to withdraw from MEW classes but stay on campus and continue to audit the class and the MEW seminar. Many students took advantage of the offer - 10 dropped the calculus class alone - and the effect was not beneficial. Those students who dropped not only expended no more effort on academics that summer, they also made it difficult for those who continued in their courses to do so. In subsequent years Lasser reverted to her policy of asking those who drop or withdraw from their University class to be out of the dorms within 24 hours; drops and withdrawals returned to normal levels.

The increase in the pool of students invited to participate in MEW had in the past necessitated turning away some MEW applicants. In 1999, additional funding was received from Duke Energy. This funding, which has been generously provided in every year since, allowed Snelsire and Lasser to offer an additional MEW section of pre-calculus. Ms.Garner recommended Ms. Sherry Biggers, also a member of the University mathematics faculty, to lead the second MEW precalculus seminar. Ms. Biggers, who has served as the coordinator for the business calculus courses, is well known for her enthusiasm for and interest in teaching freshman courses.

Proceedings of the 2003 American Society for Engineering Education Annual Conference \& Exposition Copyright (C) 2003, American Society for Engineering Education 
When the Mathematics Department offered the five-credit MthSc Pre-Calculus class for a final time during the summer of 1999, this last section reflected some changes in curriculum that were to be fully realized in the fall of 1999. The grades that MEW participants received in 1999 were lower than in previous years. As Ms. Biggers remembers, "In the last summer they did 105, the material was already reflecting the changes, so the course became more demanding. Students who would have been assigned to algebra were fast-forwarded into trigonometry and functions. The grades reflected this." For this reason, the 1999 transition year is not included in this study.

In 2000, the Math Excellence Workshop followed the new curriculum and offered seminars for both of the new pre-calculus classes and for first-semester calculus. All three courses were also offered in 2001 and will be offered in 2002. Brawley continues to teach calculus; Garner now leads the functions and trigonometry seminar, and Biggers takes charge of the algebra seminar. Each is assisted by two student tutors and each follows the Treisman concept of collaborative learning. All tutors join together Sunday through Thursday evenings of MEW to offer a voluntary, drop-in study hall from 7:00 to 10:00pm.

In the first year of the new algebra and functions/trigonometry classes, students were assigned to the classes based on their SAT scores. The Mathematics Department had in the meantime been developing the Clemson Math Placement Test (CMPT) for incoming students, which they were to take online in the summer before their freshman year. The CMPT was used in conjunction with SAT scores for MEW placement in 2000. In 2001, students were placed in courses solely on the basis of the CMPT results, and this policy will continue for the foreseeable future.

\section{Summary of current retention of Black students}

Over 80 percent of PEER students are consistently retained into the sophomore year in engineering. In comparison to national statistics, Clemson University African American engineering students are doing very well. According to ABET, the national engineering accreditation body, the average GPR of African American engineering graduates in the U.S. is 2.15. The average GPR of all PEER engineering graduates is 2.62. The ABET report also states that only five percent of African American engineering graduates have GPRs above 3.0, compared to 21.3 percent of Clemson students (ABET Report, 1990).

Through the programs coordinated by the PEER staff, Clemson's retention rates for Black engineering and science majors are significantly higher than the national average, as shown in Table 2. While the six-year graduation rate of Black students in STEM majors nationwide still hovers around one in four, Clemson is more recently graduating nearly half in engineering and science. Six-year graduation rates in any university major are just as impressive-while the nationwide average is $39 \%$, Clemson graduates $75 \%$ of Black students in some university major. This is not significantly different from the graduation rate of the white majority population. 
Table 2. Graduation rates of recent cohorts of Black students at Clemson and nationwide

\begin{tabular}{|l|l|}
\hline Black 6-year graduation rate in STEM majors, nationwide, 1996 cohort & $27 \%^{12,13}$ \\
\hline Black 6-year graduation rate in any major, nationwide, 1996 cohort & $39 \%^{14}$ \\
\hline & \\
\hline Black 6-year graduation rate in engineering and science, Clemson, 1996 cohort & $48 \%$ \\
\hline Black 6-year graduation rate in any major, Clemson, 1996 cohort & $75 \%$ \\
\hline
\end{tabular}

\section{Longitudinal study protocol}

This study focuses on participants in the Math Excellence Workshop (MEW) who took the workshop in conjunction with Pre-Calculus (MthSc 105) during the summer of their cohort year, including cohort years 1992-1998. Years prior to 1992 were not included in the study because data were not available, and 1999 was not used because the Pre-Calculus course was in transition as described earlier. The performance of students who participate in the MEW program in conjunction with Calculus I (MthSc 106) is also being studied, but is not discussed here. Similarly, MEW participants in the recently-created algebra and trigonometry/functions pre-calculus courses are not included, since those classes have not been offered long enough for longitudinal study. A control group is drawn from students who did not participate in MEW.

Demographic data collected for analysis included birth date, sex, and predicted grade point ratio (PGPR). PGPR is defined by Clemson University's Undergraduate Admissions Office, and is determined from SAT or ACT scores, high school grades, and a parameter that accounts for high school quality. Grade data for MEW and control group students for MthSc 105, MthSc 106 and MthSc 108 (Calculus II) were obtained by searching on-line transcripts. Graduation information was also collected. Students were characterized as graduating in engineering, sciences, nonengineering, or non-grad.

The study is quasi-experimental, because the control group is non-equivalent due to the selection bias and the fact that the control group is not chosen randomly. To make the control group as similar to the MEW population as possible, the control group populations were restricted on the basis of PGPR and date of birth. The range of PGPR was found for the MEW group. If a student being considered for the control group was more than 0.10 outside the range of the MEW group, that student was deleted from the control population. One student within the acceptable range of PGPR was deleted from the control group for using Advanced Placement (AP) credit to place out of Calculus I (MthSc 106). That does not mean that other students who took an AP Calculus class and/or took an Advanced Placement Calculus exam were excluded from the population - the student was only removed for placing out of the Calculus course. The approach taken for control group design allows more variability than methods such as matched-pair designs, but still constrains the control group to be as similar as possible to the MEW group on the variables of interest.

In Table 1, the "study group" columns indicate the number of students in the MEW and control study groups. The student eliminated for using AP credit for Calculus I is shown in the table.

Proceedings of the 2003 American Society for Engineering Education Annual Conference \& Exposition Copyright $\left({ }^{\circ} 2003\right.$, American Society for Engineering Education 
Students who did not have any type of grade in any of the three math courses in this study were also eliminated, as shown in Table 3.

Table 3. MEW and control group definition.

\begin{tabular}{|r|c|c|c|c|}
\cline { 2 - 5 } \multicolumn{1}{c|}{} & MEW & \multicolumn{2}{c|}{ Control } & \multicolumn{1}{c|}{} \\
\cline { 2 - 5 } & $\begin{array}{c}\text { Study } \\
\text { group }\end{array}$ & $\begin{array}{c}\text { AP } \\
\text { Credit }\end{array}$ & $\begin{array}{c}\text { Study } \\
\text { group }\end{array}$ & $\begin{array}{c}\text { Tota } \\
1\end{array}$ \\
\hline 199 & 21 & $\cdot$ & 23 & 44 \\
2 & & & & \\
\hline 199 & 32 & 1 & 9 & 42 \\
3 & & & & \\
\hline 199 & 16 & $\cdot$ & 15 & 31 \\
4 & & & & \\
\cline { 2 - 5 } 199 & 10 & $\cdot$ & 16 & 26 \\
5 & & & & \\
\cline { 2 - 5 } 199 & 21 & $\cdot$ & 8 & 29 \\
6 & & & & \\
\cline { 2 - 5 } 199 & 13 & $\cdot$ & 3 & 16 \\
7 & & & & \\
\cline { 2 - 5 } 199 & 18 & $\cdot$ & 6 & 24 \\
8 & & & & \\
\cline { 3 - 5 } 199 & $\cdot$ & $\cdot$ & 23 & 23 \\
9 & & & & \\
\cline { 3 - 5 } 200 & $\cdot$ & $\cdot$ & 12 & 12 \\
0 & & & & \\
\hline
\end{tabular}

The data was analyzed using SAS Procedures (SAS Institute Inc., Cary, NC, USA). Initial data on PGPR and birth date were analyzed for the MEW and control groups using the general linear models (GLM) procedure by year and in the aggregate. This confirmed that no significant differences existed in either of these variables between the two populations. In the cohorts by year, the largest difference between the MEW and control group PGPR was 0.13, and the largest difference in birth date between matched cohorts was less than one year. In the aggregate data, the difference between the MEW and control group PGPR is less than 0.1.

When grade data for math courses are recorded, only the grade earned in the first attempt is considered. Grade data were converted from an alphabetical form to a numeric value, where grades of A, B, C, D, F, or W were converted to 4, 3, 2, 1, 0 or blank, respectively. Again, the GLM procedure was used. Frequency counts by test group and grades were performed and percentages of students receiving different grades were calculated. Grades of $\mathrm{A}, \mathrm{B}$, or $\mathrm{C}$ were later characterized as acceptable while all other grades $(\mathrm{D}, \mathrm{F}, \mathrm{W})$ were determined to be unacceptable. This converted grade into a dichotomous "success" variable for certain parts of the study. Graduation data were compiled and students were broken into four groups based on Classification of Instructional Program codes. The four groups were graduating in engineering,

Proceedings of the 2003 American Society for Engineering Education Annual Conference \& Exposition Copyright (C) 2003, American Society for Engineering Education 
non-engineering, sciences, or non-grad. A general analysis of graduating vs. non-graduating was also completed.

While some of the more interesting outcomes are significant for many of the individual cohorts, a number of tests are conducted on the aggregate outcome of all the cohorts of a particular group combined. This is possible because the MEW Pre-Calculus program has been conducted in a similar format for all the years of the study. The program has been particularly consistent in that is has had the same administrators for the entire period.

\section{Findings of longitudinal study}

Table 4 shows the predicted GPR for each cohort of MEW Pre-Calculus participants and the corresponding control group. The data are broken down by sex and also show the general retention rate (percent of cohort graduated or still enrolled in any discipline).

Table 4. Predicted GPR and actual retention rate (in any major) for Female and Male MEW and control cohorts starting in Pre-Calculus

\begin{tabular}{|c|c|c|c|c|c|c|c|}
\cline { 3 - 8 } \multicolumn{2}{c|}{} & \multicolumn{3}{c|}{ MEW } & \multicolumn{3}{c|}{ Control } \\
\hline Year & Sex & N & PGPR & Ret \% & N & PGPR & Ret \% \\
\hline \multirow{2}{*}{1992} & F & 10 & 2.49 & 50.0 & 11 & 2.44 & 81.8 \\
\cline { 2 - 8 } & M & 11 & 2.39 & 45.5 & 12 & 2.46 & 33.3 \\
\cline { 2 - 8 } & F & 15 & 2.44 & 73.3 & 3 & 2.37 & 66.7 \\
\hline \multirow{2}{*}{1994} & F & 17 & 2.49 & 47.1 & 6 & 2.49 & 66.7 \\
\cline { 2 - 8 } & M & 7 & 2.53 & 66.7 & 10 & 2.53 & 60.0 \\
\hline \multirow{2}{*}{1995} & F & 3 & 2.44 & 100.0 & 7 & 2.59 & 71.4 \\
\cline { 2 - 8 } & M & 7 & 2.50 & 57.1 & 9 & 2.53 & 44.4 \\
\hline \multirow{2}{*}{1997} & F & 10 & 2.60 & 70.0 & 5 & 2.72 & 100.0 \\
\cline { 2 - 8 } & M & 11 & 2.47 & 63.6 & 3 & 2.57 & 66.7 \\
\cline { 2 - 8 } & F & 10 & 2.60 & 70.0 & 0 &. &. \\
\hline 1998 & F & 3 & 2.73 & 66.7 & 3 & 2.79 & 66.7 \\
\cline { 2 - 8 } & M & 6 & 2.37 & $66.7^{*}$ & 4 & 2.45 & 25.0 \\
\hline
\end{tabular}

Significant differences from control, chi-square, $\mathrm{p}<0.05$ : $^{*}$ Retention rate

The lack of variability of the Predicted GPR of the cohorts is noticeable, intentional, and due to the control group design. These data are summarized later when the behavior of the aggregate of all these cohorts is discussed, but a single individual cohort (1998) is identified here that shows a significant difference even with the small population of the cohort. 
Table 5 shows the grade performance and persistence (how far they made it through the mathematics sequence) for the MEW and control cohorts starting in Pre-Calculus. The grade performance is based on the first grade earned by each student in a particular course without regard for any subsequent performance. Since the grade performance data only pertain to the first time a student takes the course, persistence is measured by observing how many students from the cohort continue on to the next course. The statistical study of persistence will be addressed later.

Table 5. Math grades and persistence for MEW and control cohorts starting in Pre-Calculus

\begin{tabular}{|c|c|c|c|c|c|c|c|c|c|c|c|c|}
\hline & \multicolumn{6}{|c|}{ MEW } & \multicolumn{6}{|c|}{ Control } \\
\hline & \multicolumn{2}{|c|}{ MthSc 105} & \multicolumn{2}{|c|}{ MthSc 106} & \multicolumn{2}{|c|}{ MthSc 108} & \multicolumn{2}{|c|}{ MthSc 105} & \multicolumn{2}{|c|}{ MthSc 106} & \multicolumn{2}{|c|}{ MthSc 108} \\
\hline & $\mathrm{N}$ & GPR & $\mathrm{N}$ & GPR & $\mathrm{N}$ & GPR & $\mathrm{N}$ & GPR & $\mathrm{N}$ & GPR & $\mathrm{N}$ & GPR \\
\hline 1992 & 21 & $2.85^{*}$ & 18 & 2.06 & 13 & 2.06 & 23 & 2.22 & 20 & 1.80 & 13 & 2.00 \\
\hline 1993 & 32 & $3.03^{*}$ & 23 & 2.09 & 16 & $2.19^{\#}$ & 9 & 2.11 & 6 & 1.50 & 2 & 0.00 \\
\hline 1994 & 16 & 3.31 & 14 & 2.36 & 11 & 1.64 & 15 & 2.67 & 9 & 2.11 & 5 & 2.40 \\
\hline 1995 & 10 & $2.80^{* \#}$ & 7 & 1.71 & 8 & 1.60 & 16 & 1.53 & 12 & 1.42 & 5 & 1.25 \\
\hline 1996 & 21 & 2.47 & 17 & $3.00^{*}$ & 9 & 2.33 & 8 & 2.14 & 4 & 1.59 & 3 & 1.89 \\
\hline 1997 & 13 & $3.20^{*}$ & 7 & 2.00 & 4 & 1.50 & 3 & 0.67 & 3 & 1.33 & 0 & . \\
\hline 1998 & 18 & $3.28^{* \#}$ & 16 & 1.25 & 7 & 2.14 & 6 & 0.80 & 2 & 2.50 & 0 & . \\
\hline
\end{tabular}

Significant differences from control, chi-square, $\mathrm{p}<0.05$ : ${ }^{*}$ average grade, ${ }^{*}$ completion rate

For Pre-Calculus, the course taken concurrently by the MEW participants shown here, the math grade performance of most of the individual cohorts of MEW students is significantly better than that of the corresponding control group. While the performance of the MEW cohorts in the later math classes (Calculus I and Calculus II) still appears to be better than the control group performance in these classes, the significance has eroded due to mortality. The loss of students from the study makes it more difficult to achieve statistical significance. Furthermore, the control group is losing more students, which improves the average performance of the remaining students (i.e., poor performers are more likely to drop).

A graph of the math grade-point ratio (GPR) for each cohort for each class is given in Figure 1, in which each bar represents the math performance of one annual cohort (1992-1998) in either the MEW or control group in the course indicated on the categorical axis. This makes it easier to make certain observations. The declining grade performance in the courses subsequent to the MEW program appears not to result from the students losing the benefit of the program, because the same decline is observed for the control group. This decline is likely due to the increasing difficulty of the courses. The significance of the difference between students in the MEW and control groups in the Pre-Calculus course is particularly noticeable, especially in that only one cohort from the control group (1994) outperformed the lowest performing cohort of the MEW group (1996). It can also be observed that there is more variability in the control group from one cohort to another than there is in the MEW group. Note that the zero-value bar for the control group in 1993 is an actual data point, whereas the lack of bars for 1997 and 1998 is due to missing values - no students from those cohorts progressed so as to take Calculus II.

Proceedings of the 2003 American Society for Engineering Education Annual Conference \& Exposition Copyright $\left({ }^{\circ} 2003\right.$, American Society for Engineering Education 


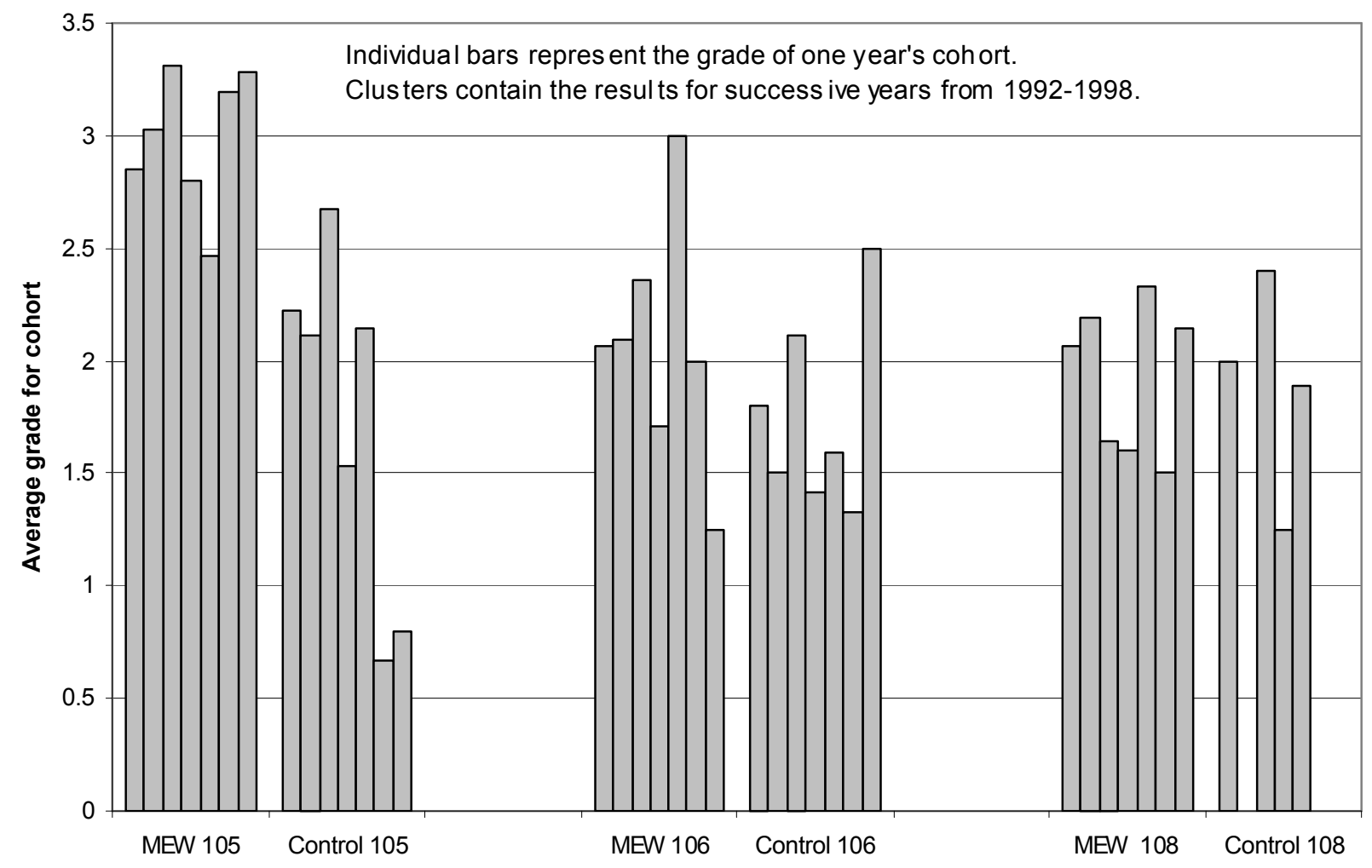

Figure 1. MEW and control grade performance in Pre-Calculus, Calculus I and Calculus II for cohorts of students starting in Pre-Calculus from 1992-1998.

The distribution of grades in each of the courses is also revealing, as shown in Figures 2-4. These represent the aggregate performance of all cohorts from 1992-1998. The data is normalized to display the percentage of the population, so the total area of each is $100 \%$. In the case of the grade distribution in Pre-Calculus, shown in Figure 2, the MEW group's performance advantage is clear - a large percentage of the students received a grade of $\mathrm{C}$ or better (required to continue in mathematics), and none received a grade of $\mathrm{F}$. A significant portion of the control population is in the lower part of the graph. It is notable that the highest part of the MEW distribution is clearly at a grade of $\mathrm{A}$, whereas the distribution of control grades is a maximum at $\mathrm{B}$ or $\mathrm{C}$.

The improvement in the grade distribution of MEW participants over the performance of the control group is less notable in Calculus I and Calculus II, but it is still of interest. Figure 3 shows the distributions for Calculus I, where the MEW distribution is clearly centered on a grade of C, whereas the bulk of the area of the control distribution is due to students with grades of D, F, or W. In Figure 4, Calculus II performance continues to show benefit for the MEW population. Here, the peak for the MEW group is clearly at a grade of $\mathrm{B}$, although there is significant area over the lower grades. The control group, however, has a distribution that increases in the range of poor performance with only a small local maximum at a grade of $\mathrm{C}$. 


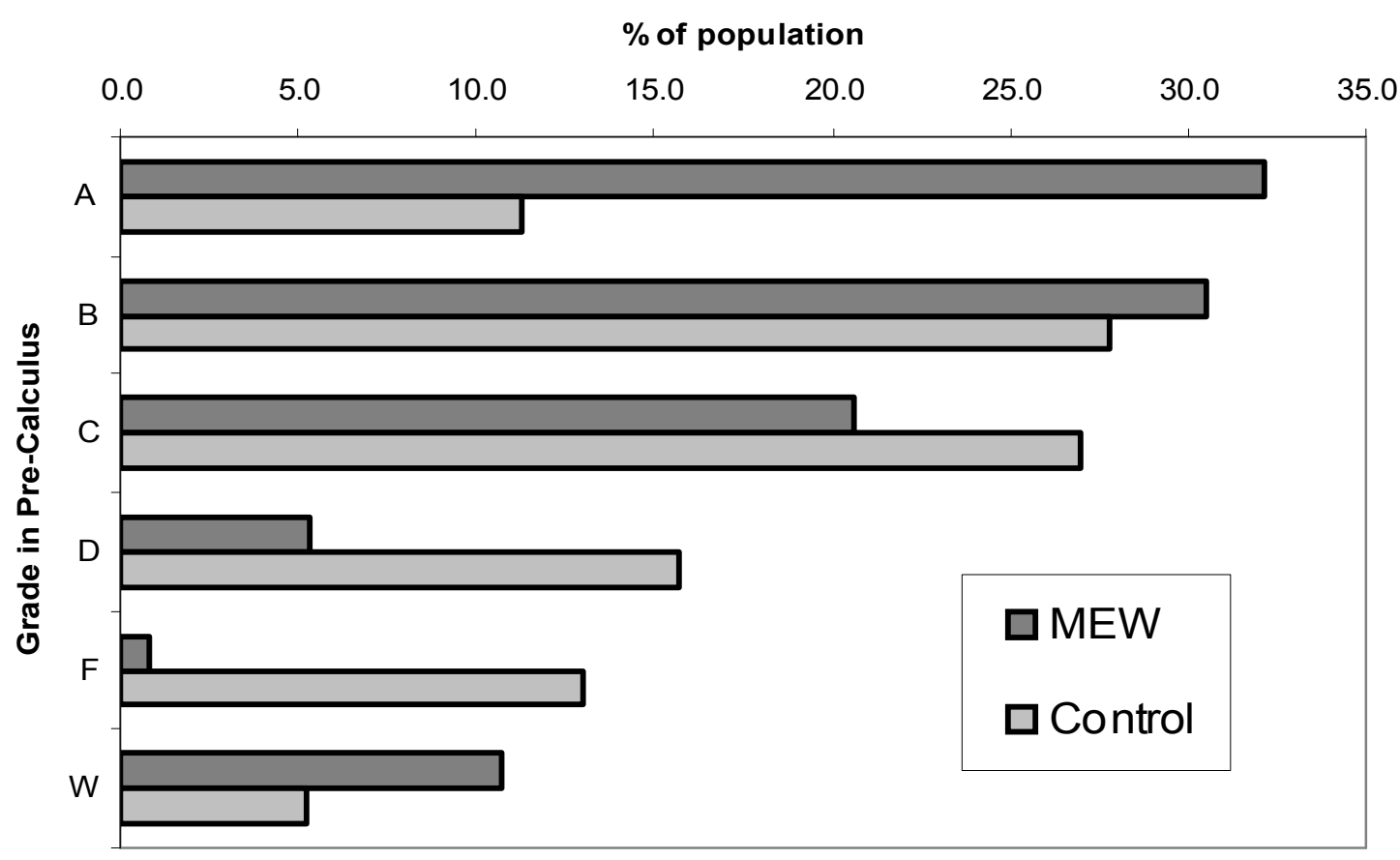

Figure 2. Distribution of MEW and control grade performance in Pre-Calculus for students starting in Pre-Calculus, aggregate of 1992-1998 cohorts.

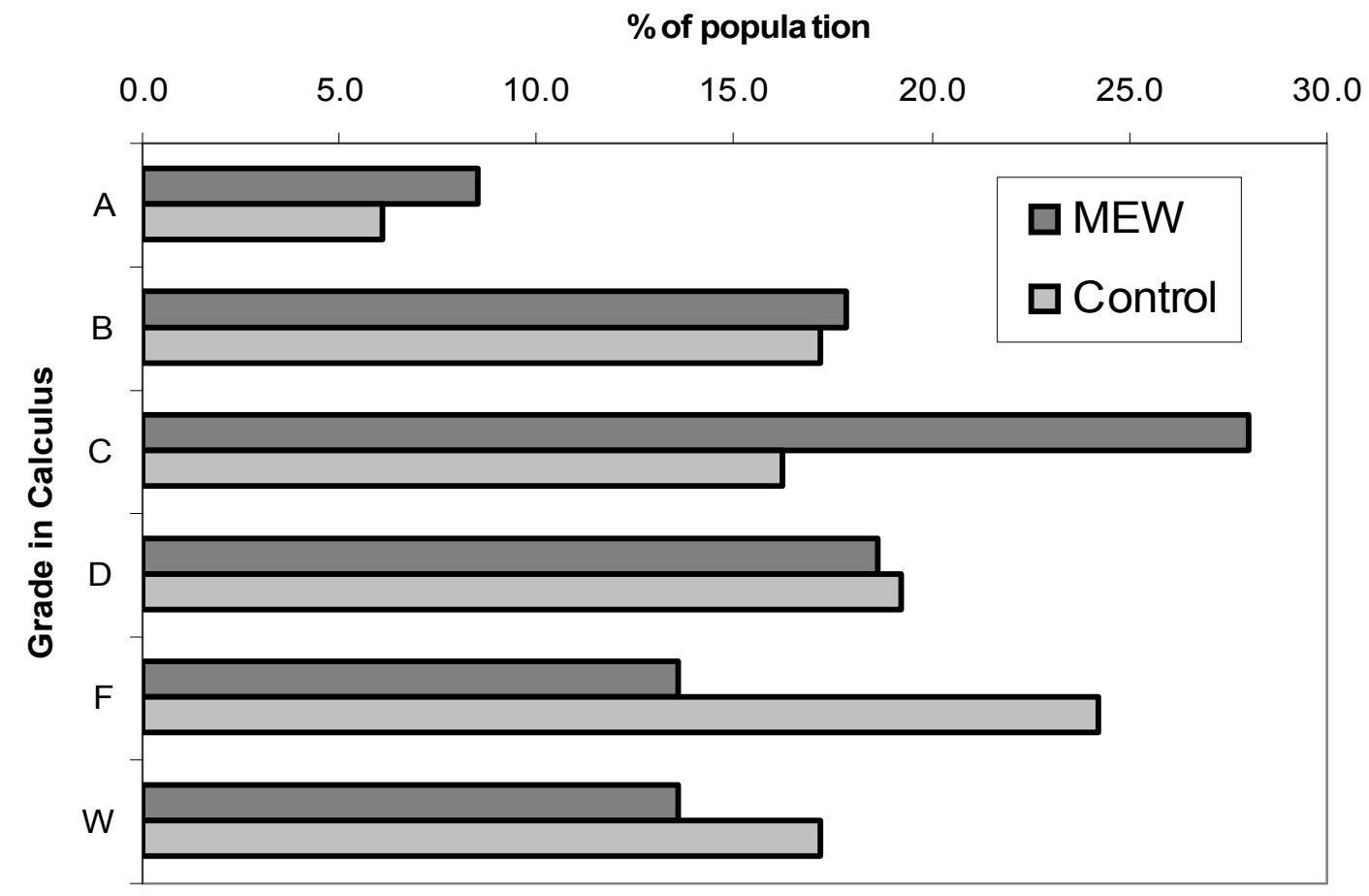

Figure 3. Distribution of MEW and control grade performance in Calculus I for students starting in Pre-Calculus, aggregate of 1992-1998 cohorts.

Proceedings of the 2003 American Society for Engineering Education Annual Conference \& Exposition Copyright (C) 2003, American Society for Engineering Education 


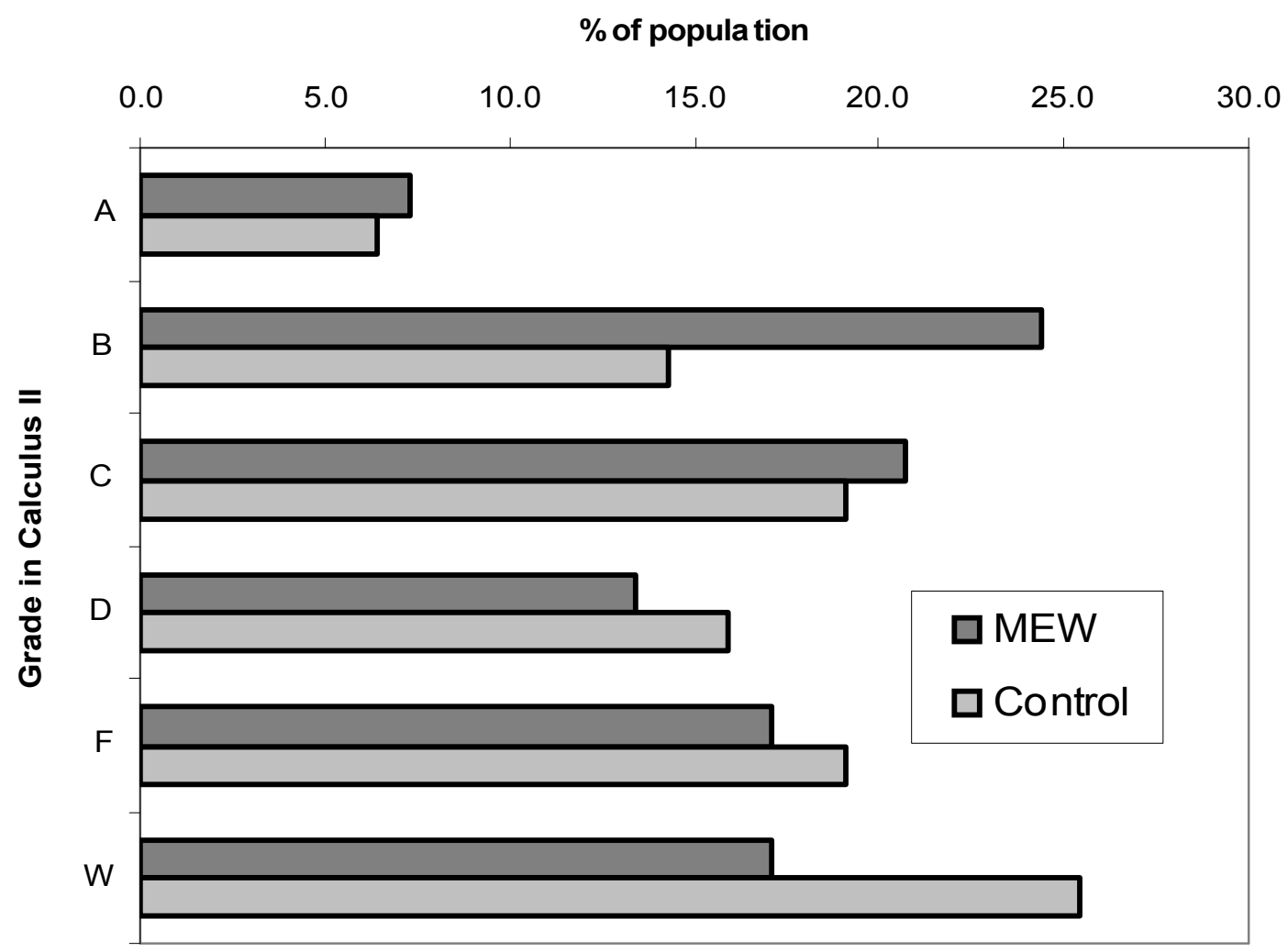

Figure 4. Distribution of MEW and control grade performance in Calculus II for students starting in Pre-Calculus, aggregate of 1992-1998 cohorts.

Table 6 summarizes the grade performance of the MEW and control groups starting in PreCalculus in the three courses from the previous figures. "Acceptable" grades are A, B, and C, since a grade of $\mathrm{C}$ or better is required for all prerequisite courses at Clemson, and is thus necessary in order to proceed in the mathematics sequence. The completion rates for both PreCalculus and Calculus I are significant and the average grade performance is significant for PreCalculus - nearly a full letter grade higher. The completion rate for Calculus II and the grade performance for Calculus I and Calculus II are observed to be higher than the control group, but these differences were not significant.

Table 6. Summary of grade performance of MEW and control groups starting in Pre-Calculus

\begin{tabular}{|c|c|c|c|c|c|c|}
\cline { 2 - 7 } \multicolumn{1}{c|}{} & \multicolumn{2}{c|}{ Pre-Calculus } & \multicolumn{2}{c|}{ Calculus I } & \multicolumn{2}{c|}{ Calculus II } \\
\cline { 2 - 7 } \multicolumn{1}{c|}{} & MEW & Control & MEW & Control & MEW & Control \\
\hline N acceptable & 109 & 76 & 64 & 39 & 43 & 25 \\
\hline $\mathrm{N}$ & 131 & 115 & 118 & 99 & 82 & 63 \\
\hline$\%$ & $83^{*}$ & 66 & $54^{*}$ & 39 & 52 & 40 \\
\hline GPR & $2.98^{*}$ & 2.09 & 1.87 & 1.54 & 1.90 & 1.64 \\
\hline
\end{tabular}

${ }^{*}$ Significant differences from control, chi-square, $\mathrm{p}<0.05$ 
Table 7 summarizes the graduation rate and the rate of successful completion of Calculus II in the MEW and control groups. Both trends are good, but fail to be statistically significant. The graduation rate (of both MEW and control) will improve as the study continues, because students in the 1997 and 1998 cohorts have not reached the 6-year graduation mark yet. Statistics are not included here that subdivide the graduate population as to whether the students graduated in engineering, science, or a non-technical major, because this further reduces the number of students in a particular pathway to the point where a comparison has no meaning. Since all engineering majors need to complete successfully (with a grade of $\mathrm{C}$ or better) Calculus II, the percentage of students in the MEW and control groups achieving this is shown as an indicator of the percentage likely to continue in engineering. While a $10 \%$ gain is observed, this is not significant.

Table 7. Summary of number of students graduated and percent of students successfully completing Calculus II for MEW and control groups starting in Pre-Calculus.

\begin{tabular}{|c|c|c|}
\cline { 2 - 3 } \multicolumn{1}{c|}{} & MEW & Control \\
\hline N graduate & 62 & 43 \\
\hline $\mathrm{N}$ & 131 & 115 \\
\hline$\%$ & 47 & 37 \\
\hline$\%$ completed 108 & 33 & 22 \\
\hline
\end{tabular}

\section{Comments on the validity of this study}

It should be noted that a statistically significant cohort effect is generally observed, indicating that some cohorts are more successful on a variety of outcomes than other cohorts. This is common in research on student groups that have the chance to associate with each other-some groups bond better, and some implementations are more effective. What is important to the validity of this study is that there was no significant systemic change of the program over time period observed.

The control group in this study is designed to minimize the threat of the self-selection of students into the program to the validity of the study. The more significant threat to the study-the accelerated drop-out rate of the students in the control group - did not prevent at least one postprogram outcome from being significant. The improvement of Clemson students over time is not considered a threat to this study because of the design of the control group. If this had been a factor, a pattern would be expected to manifest in the study of successive cohorts, and no such pattern is present.

The success of Black students in Clemson University's College of Engineering and Science is certainly improved by other activities conducted by the Programs for Educational Enrichment and Retention (PEER) staff. This is not considered a threat to the validity of this study because there is clear benefit to outcomes prior to the fall semester (when the other PEER programs start up) and because students from the control group are invited to participate in those programs when they matriculate. 


\section{Conclusions}

Students who participate in the Math Excellence Workshop program in conjunction with PreCalculus derive benefits to their grades in Pre-Calculus and the likelihood of their successful completion of Pre-Calculus and Calculus I. The trends for all other outcomes including Calculus I and Calculus II grades, Calculus II completion, and graduation are positive, but are not statistically significant.

The value of the Treisman model is further demonstrated, and the success of the MEW program certainly contributes to Clemson's graduation rate for Black engineering and science students, which is more than 20 percent above the national average.

Further evidence of the benefit of the MEW program is expected both as more time passes for students to achieve the desired outcomes and as the study is expanded to include students who participated in the MEW program in conjunction with Calculus I.

\section{Acknowledgments}

The PEER staff is grateful to the Savannah River Nuclear Site for funding the startup of this very successful program. The ongoing support of the College of Engineering and Science, the National Science Foundation South Carolina Alliance for Minority Participation, and Duke Energy is also greatly appreciated.

\section{Author biographies}

\section{MATTHEW W. OHLAND}

is an Assistant Professor in Clemson University's General Engineering program and is the President of Tau Beta $\mathrm{Pi}$, the national engineering honor society. He received his Ph.D. in Civil Engineering with a minor in Education from the University of Florida in 1996. Previously, he served as Assistant Director of the NSF-sponsored SUCCEED Engineering Education Coalition. His research is primarily in freshman programs and educational assessment.

\section{RONNIE CHRESTMAN}

is a Senior Statistician \& Research Analyst in Clemson University's Office of Institutional Research. He received his Ph.D. in Agronomy from Clemson University in 1992. He is currently on the Board of Directors for the South Carolina Association of Institutional Research. Part of his research responsibilities includes student cohort studies, classroom utilization, and facilities.

\section{SUSAN J.S. LASSER}

has served as director of the PEER Office in the College of Engineering and Science at Clemson University since its inception in 1987. She received her Master's of Education from Clemson University in 1986. The success of her programs for minority retention has been recognized nationally, and in 1996, Lasser was among the first winners of the national Presidential Award for Excellence in Science, Mathematics and Engineering Mentoring.

\section{References}

Proceedings of the 2003 American Society for Engineering Education Annual Conference \& Exposition Copyright (C) 2003, American Society for Engineering Education 


\footnotetext{
${ }^{1}$ Duncan, H., \& Dick, T. (2000). Collaborative workshops and student academic performance in introductory college mathematics courses: A study of a Treisman Model Math Excel program. School Science and Mathematics, 100(7), 365-373.

${ }^{2}$ Murphy, T., Stafford, K., \& McCreary, P. (1998). Subsequent course and degree paths of students in a Treismanstyle workshop calculus program. Journal of Women and Minorities in Science and Engineering, 4, 381-396.

${ }^{3}$ National Science Board, Science andEngineering Indicators - 2002. Arlington, VA: National Science

Foundation, 2002 (NSB-02-1), http://www.nsf.gov/sbe/srs/seind02/c2/c2s2.pdf, p. 2-14.

${ }^{4}$ National Science Board, Science andEngineering Indicators - 2002. Arlington, VA: National Science

Foundation, 2002 (NSB-02-1), http://www.nsf.gov/sbe/srs/seind02/c2/c2s2.pdf, p. 2-14.

${ }^{5}$ National Science Board, Science andEngineering Indicators - 2002. Arlington, VA: National Science

Foundation, 2002 (NSB-02-1), http://www.nsf.gov/sbe/srs/seind02/c2/c2s2.pdf, p. 2-14.

${ }^{6}$ Report to the South Carolina Committee on Higher Education, 1991, Clemson University.

${ }^{7}$ Treisman, P.U. (1985). "A Study of the Mathematics Performance of Black Students at the University of California, Berkeley, Doctoral Dissertation.

${ }^{8}$ Treisman, P. U. (1992). Studying students studying calculus: A look at the lives of minority mathematics students in college. The College Mathematics Journal, 23(5), 362-372.

${ }^{9}$ Treisman, P. U., \& Surles, S. (2001). Systematic reform and minority student high achievement. Washington, DC: Institute of Medicine (NAS). (ERIC Document Reproduction Service No. ED 460199)

${ }^{10}$ Collins, Rachel E., General Engineering home page, as of January 12, 2003, http://www.ces.clemson.edu/ge/

${ }^{11}$ Clemson University College of Engineering and Science History, http://www.ces.clemson.edu/about/history.htm

${ }^{12}$ Consortium for Student Retention Data Exchange report, http://www.occe.ou.edu/csrde/

${ }^{13}$ Clemson World, Winter 2002, Clemson University, Clemson, SC, p. 31.

${ }^{14}$ Consortium for Student Retention Data Exchange report, http://www.occe.ou.edu/csrde/
} 